\title{
A SIMULATION GAME APPROACH TO SUPPORT LEARNING AND COLLABORATION IN VIRTUAL ORGANISATIONS
}

\author{
Max Schwesig, Klaus-Dieter Thoben, Jens Eschenbächer \\ $B I B A$ at the University of Bremen, GERMANY \\ max@biba.uni-bremen.de, tho@biba.uni-bremen.de, esc@biba.uni-bremen.de
}

\begin{abstract}
As products are getting more complex, it often requires various enterprises with certain key competencies to produce a product in collaboration in e.g. a virtual organization. The resulting specialization leads to an increased demand for knowledge. Thus, especially interorganisational learning gains importance. As a consequence of the stated developments, the way of working and thus the educational requirements have changed as well. Performance skills about the processes and challenges within interorganisational product development and -learning are becoming vital to efficiently participate in future working scenarios. This paper describes the research approach, development and evaluation of a web based group simulation game that has been built to address these new educational demands.
\end{abstract}

\section{INTRODUCTION}

In recent discussions there is a growing trend to consider products and services more as a customer benefit or a solution to a customer problem, which has been described by the term extended product. Such complex extended products and services cannot be created by single enterprises but from enterprise networks such as virtual organisations (Thoben et al. 2001). The resulting specialization within companies accelerates innovation speed and thus increases the demand for knowledge. As half time of knowledge continuously decreases, the organizational capacity for learning is being identified as one of the key abilities for organizations to survive. As a consequence of the stated developments, the way of working and thus the educational requirements that engineers face have changed as well. Communication skills, collaborative skills as well as performance skills about the processes and challenges within organizational and interorganisational learning and -product development are becoming vital. Appropriate tools to mediate such skills are simulation games. 
Existing games in the field of organisational learning and the closely related knowledge management (Büchel, Probst 2000) as the simulation game "KM Quest" (KITS 2003) and "Wissensmanagement Planspiel für soziale Organisationen" (BBJ 2002) emphasize on the mediation of basic principles of knowledge management as well as the implementation and intervention related aspects.

Existing simulation games in the field of product development like "COSIGA" (Pawar et al. 1995) "City Car Simulation" (Goffin, Mitchell 2002) and "GLOTRAIN" (Windhoff 2001) focus on the mediation of certain approaches or emphasize on important success factors in product development or even distributed production. So far, (inter)organisational learning, company collaboration in a virtual organisation and product development have not been considered in a single gaming approach. In order to address the mentioned educational requirements, we proposed a web enabled group simulation game simulating processes and challenges in interorganisational working and learning in a virtual organisation.

\section{RESEARCH APPROACH}

As the initial evaluation and validation of the COSIGA simulation have been very encouraging (Riedel et al. 2001), this four step product development and manufacturing process will be used as a basis for the design of the new simulation. Since this new game emphasizes the active experience of intraorganizational and interorganisational learning, it is necessary to identify key processes and challenges within intraorganizational and interorganizational learning. In order to simulate interorganisational manufacturing, it is important to identify organisational principles of distributed manufacturing as well as the life cycle of a manufacturing network of companies. Together, these design elements will then be used to shape the simulation game.

\subsection{Processes and challenges of organizational learning}

After having regarded the existing simulation game for Concurrent Engineering"Cosiga", which serves as a conceptual basis for the new game, we identify processes and challenges within organisational and interorganisational learning. Together, these game elements will form the SHARE gaming approach.

"Cosiga" is a multimedia computer based simulation game being played by five individuals in the same room (co-located) or in a distributed group (virtual) interacting in a product development scenario and using the Internet and telecommunications. As initial evaluation and validation with target users have been very encouraging (Riedel et al. 2001), this four step product development process will be used as a basis for the design of the SHARE game. Since this new game emphasizes the active experience of organizational and interorganisational learning, it is necessary to identify key processes and challenges within organizational and interorganizational learning. Organisational learning is interpreted from a multi level perspective, comprising of the individual, group, organizational and inter- 
organizational level (Nonaka 1994), since this point of view enables us to regard main levels of action within an enterprise. According to this perspective, the following working definitions of the different learning levels have been created:

Individual level learning focuses on individual knowledge acquisition without further social interaction. Group level learning happens, if more that one individual consciously or unconsciously acquires knowledge interactively. Organisational level learning focuses on perspective taking between groups in a company (Sumner et al. 1999). As organisations are typically composed of multiple interacting communities, each with highly specialized knowledge, skills and technologies, knowledge intensive firms require these diverse communities to bridge their difference to create a new shared perspective Interorganisational learning happens in two ways: either through the transfer of existing knowledge from one organization to another, or through the creation of new knowledge (Larsson et al.1998). Group level learning ,organizational level learning and interorganisational learning are affected by "people barriers" like proprietary thinking and skepticism towards the sharing of knowledge and various fears (Barson et al. 2000). Additionally, interorganisational learning is affected by organisational boundaries like space, time, (cultural) diversity, structure and distribution of knowledge and results (Bosch-Sijtsema 2001).

Especially organizational level learning is difficult to simulate as it requires the professional and technical identification of the players with their departments specialized background. As this effect cannot be reached in a multiple hour simulation game, we mainly consider individual- group- and interorganisational level learning in the simulation game. Together with the mentioned barriers and boundaries, these game elements form a gaming approach will be implemented in two game scenarios..

\subsection{PRINCIPLES OF DISTRIBUTED MANUFACTURING IN A VIRTUAL ORGANISATION}

According to Windhoff (Windhof 2001, p. 31) game relevant characteristics of distributed manufacturing are cooperation, interconnectedness, symbiosis and probability. As key competencies and knowledge are distributed, companies have to cooperate to combine them in order to be successful. Due to this cooperation, the different systems are interconnected, so that especially interorganisational business processes and the related material - and information flows have to be considered in a simulation. As the companies are standing in symbiosis to other companies, the success of an individual company depends on the performance of the other partners. On the other handed side, the optimisation of one company does not automatically lead to the optimisation of the network. Additionally, the behaviour of the overall system cannot be predicted precisely, which might lead to complex nontransparent working situations. Figure 1 illustrates the mentioned characteristics of distributed manufacturing and their implementation. 


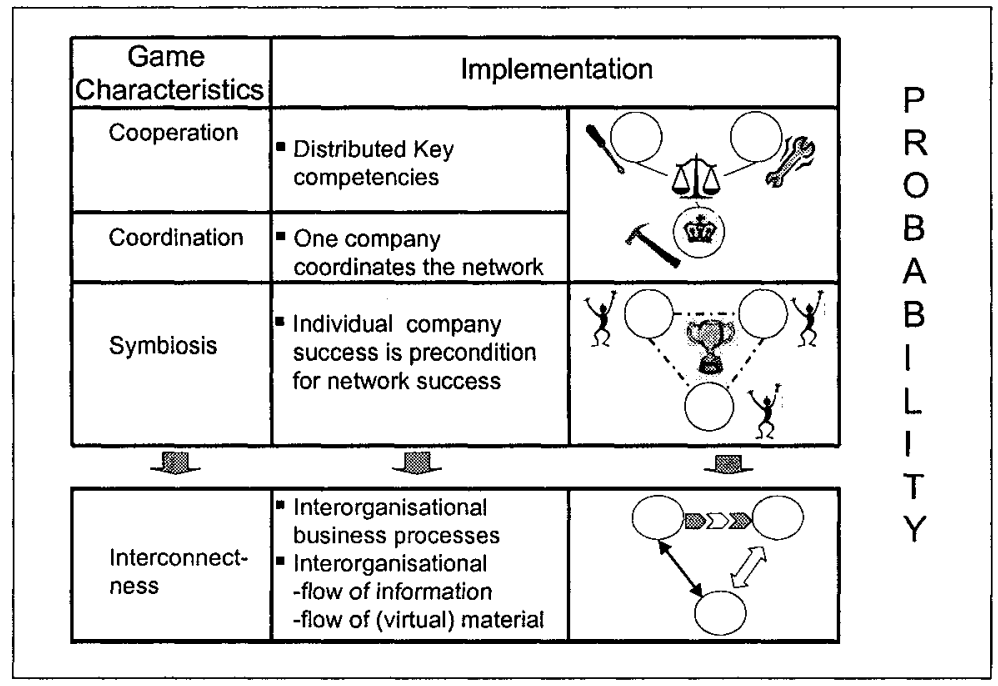

Figure 1: Characteristics of distributed manufacturing and their implementation

\subsection{THE LIFE CYCLE OF A MANUFACTURING NETWORK}

As manufacturing networks are dynamic and constantly changing, temporary consortia of enterprises that strategically join skills and resources to better respond to business opportunities are gaining importance. The life cycle of such virtual manufacturing organisations consists of four phases: creation, operation, evolution and dissolution (Camarinha-Matos, Afsarmanesh 1999). As the simulation model is rigid and the inclusion of additional partnering organizations would increase the models complexity, the evolutionary aspect of virtual organizations is not considered in the simulation. Since the simulation does not aim on simulating the complete life cycle of a virtual organization, the dissolution of the virtual organization is not considered, either. Thus, the simulation considers the creation and operation of the virtual organisation. Figure 2 illustrates the life cycle of such a virtual organisation.

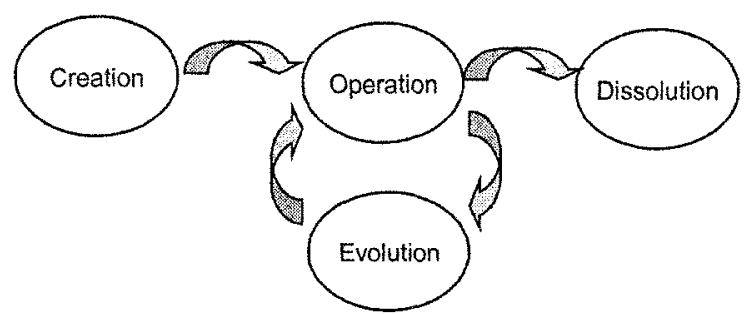

Figure 2. The life cycle of a virtual organization (Camarinha-Matos and Afsamarnesh 1999, S. 17) 


\section{The simulation game approach}

The following descriptions discuss the main Game levels with a specific focus of the developed functionality. Additionally the web-solution is presented and explained.

\subsection{Level 1 of the SHARE game}

In the first level, nine players have to specify, design and produce a jetski in one company. They act as employees of an organisation that covers the basic economical functions. Each department is responsible for the successful completion of at least one step within the product development process. The game engine measures time, the expenditures as well as the product quality in order to create a competitive situation that increases the motivation of the players. The players are divided into three groups resembling the departments of the company. These three groups are distributed in disperse locations in order to enable the players to experience working in distributed environments. Each player uses an individual web interface to accomplish his given tasks within the simulated product development process. They have the opportunity to communicate using the built in chat function as well as the telephone.

In order to simulate organisational knowledge exchange realistically, essential information that is required to accomplish the product development process is distributed unequally, so that the players have to cooperate and to communicate to be successful. Following their role descriptions, some players act non collaborative to form "people barriers". The information seeking players have to convince their non collaborative colleagues to share their knowledge. In order to support this process, they can apply "trust enhancing measures" like inviting their opposite for dinner or for a sports trip. Off course, these illustrated symbolic measures only present a limited variety of measures that can be applied in real life. However, we aim on mediating that relationship building can be accelerated by special attention and symbols of good will. By letting the players experience the destructive effect of non collaborative behaviour, we want them to understand the benefits of knowledge sharing. The layout of the first level is illustrated in Figure 3. 


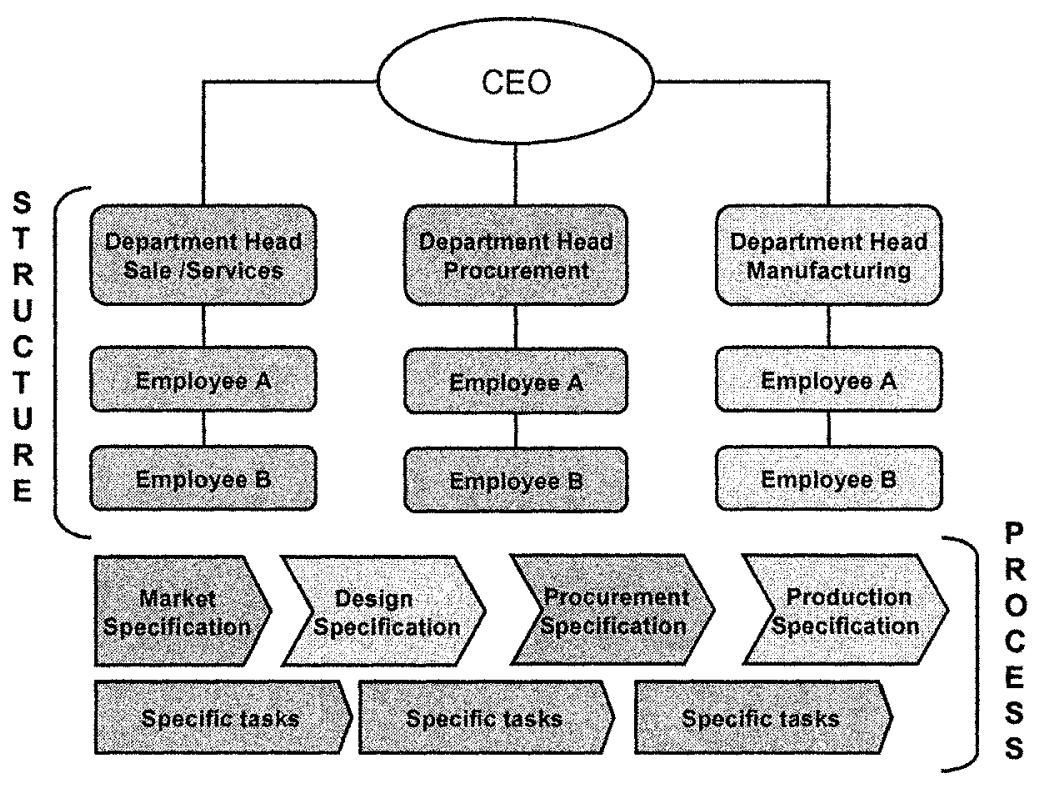

Figure 3. Structure and process in level 1

After the game, the players come together physically in order to reflect on what has happened and why certain events took place. Within this debriefing phase, they identify problems and initiating events that occurred in the areas of communication, collaboration and of course trust. Together, they develop problem solutions in order to improve their communicative- and cooperative skills.

\subsection{Level 2 of the SHARE game}

Within the second level, the players use the acquired knowledge and skills in the interorganisational contract negotiations in order to then specify, design and produce an extended product interorganisationally: a cell phone enriched by certain services. While the simulated service company takes consortial leadership and develops services, the two simulated manufacturing companies develop and produce the cell phone in a generic approach. Again, the players are divided into three groups resembling the particular companies in the production network. These three groups are distributed in disperse locations in order to enable the players to experience working in distributed environments. As consortia responsibilities are distributed unequally, the partners have to cooperate to enable constant flow of information that will then lead to a constant flow of material. In order to develop and produce this extended product, the overall success depends on every partners successful contribution. In order to simulate interorganisational learning related challenges realistically, this constant flow of information is affected by the simulated organisational boundaries space, time, diversity and structure. In order to successfully accomplish the overall scenario, the players are required to find 
appropriate solutions in order to overcome the barriers. The layout of the second level is illustrated in Figure 4

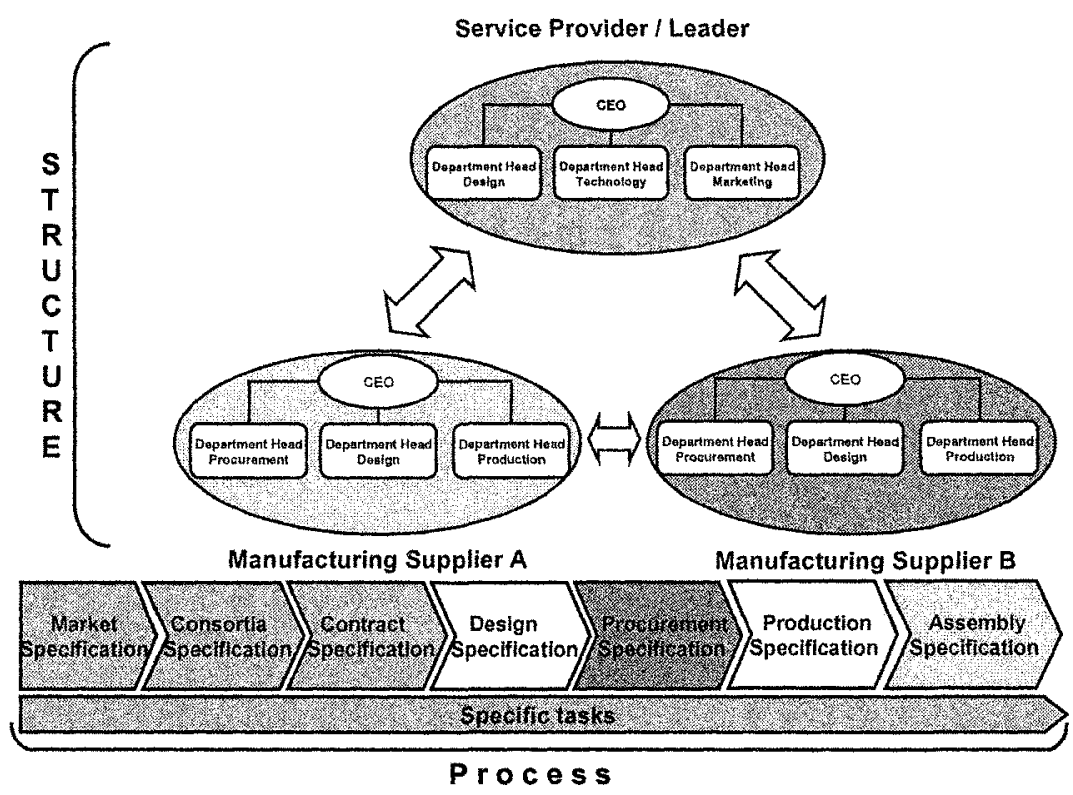

Figure 4. Structure and process in level 2

After the game session, the players come together physically again in order to reflect on what has happened and why certain events took place. Within this debriefing phase, they identify problems and initiating events that occurred in the areas of interorganisational knowledge exchange and related boundaries. Together, they develop strategies how to overcome such boundaries in, order to acquire performance skills in interorganisational working and - learning.

\subsection{The web interface}

The described structures are implemented in a web interface. This web interface displays the main game features to each player. After having logged into the web interface by using individually assigned login data, the players enter their individual game interface. While the left handed side contains links to information about the company structure and the different players, the items on the right handed side are linked to templates representing the product development process that has to be completed. Additionally, the player can access information about the scenario, the final product and the particular individual task including information about the responsibilities within the company as well as role descriptions at the upper part pf the screen. This information has proved to be essential to provide basic orientation to the players during the game. Status information is displayed at the lower part pf the screen. Apart from that, the players can apply the described trust enhancing 
measures to other players in order to build up a trustful working relation. In order to communicate with each other, the players can use the built in chat function at the screen bottom.

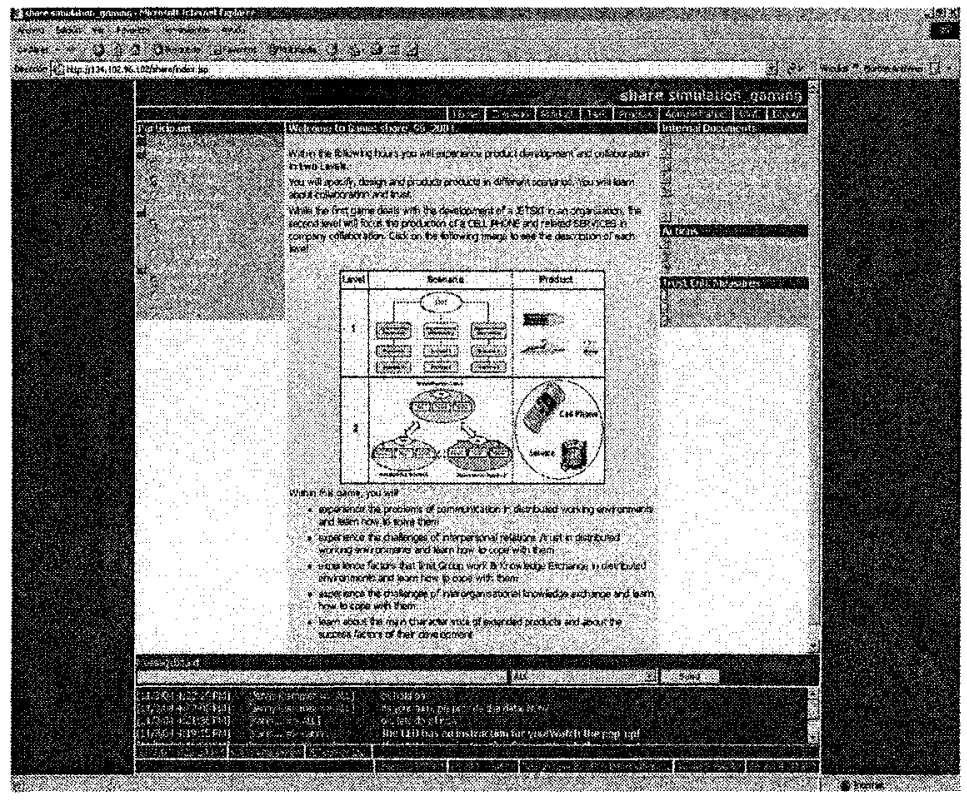

Figure 5. The SHARE Web interface

\section{CONCLUSION}

We have created a web based group simulation game focussing on the learners experience of (interorganisational) product development as well as organisational and interorganisational learning processes and challenges. Therefore we have combined a gaming approach used in the simulation game "COSIGA" with identified processes and challenges in (inter)organisational learning. An initial version of the game has been evaluated and validated in four gaming sessions with 36 students and industry representatives. Each gaming session consisted of two levels being played in two complete consecutive days.

In order to evaluate the suitability of the implemented game characteristics and the individual learning outcome, two questionnaires have been created. We felt that this form of evaluation was most appropriate, since it enabled us to get a rough idea about he game characteristics and its effects at a reasonable evaluation effort.

This initial evaluation of the first level showed that the players rated an improvement in their communication skills in distributed environments. Additionally, the value of interpersonal relations and trust was experienced as the precondition for successful collaboration. Occasionally, the players felt overstrained by the initial complexity of the gaming model. This will be improved by detailing 
the introduction to the game and its features. As a consequence of the sequential product development process, some players suffered from limited involvement in the game at certain times. This will be addressed by implementing additional supporting tasks that have to be completed by idle departments and by the enrichment of the department heads responsibilities to assure equal workload among the employees of a department.

This evaluation of the second level showed that the players appreciated the realistic simulation of interorganisational product development and - collaboration in a virtual organisation. They suffered from the implemented organisational boundaries and recognized their challenging effects, as they especially enjoyed the simulation of diverse cultures and different time zones. At the beginning, the players felt overstrained by the initial complexity of the simulated interrelations between companies. This will be improved by detailing the introduction to the game and explaining the particular company interrelations.

During this initial testing phases, the web based simulation game suffered from minor system instabilities, so that the learning outcome was not optimal for every player. This is optimised by extensive testing using simulated game sessions to identify and solve the occurred server problems. Additionally, the games usability is currently optimised by enhancing the graphic user interface.

Furthermore, it is planned to develop an adjustable game that is able to simulate different kinds of vertical and horizontal collaborations. An accordant system architecture is in development. Apart from that, modern wireless technologies will be integrated to enable an easy implementation in working and learning environments and to realistically present of future ubiquitous learning environments for engineers. This is partly addressed within the upcoming EU-NMP research project PRIME (Providing Real Integration in Multi-disciplinary Environments)

\subsection{Acknowledgments}

The paper is mainly based on work performed in the project GEM funded by the European Community under the Framework programme 5 (IST-2001-32059) and comprises a minor contribution form the IP ECOLEAD (IFP6-IP 506958).

\section{REFERENCES}

1. Barson, R.; Foster, G.; Struck, T.; Ratchev, S., Pawar, K.; Weber, F.; Wunram, M. (2000): Inter- and Intra-Organisational Barriers to Sharing Knowledge in the Extended Supply-Chain. Proceedings of the eBusiness and eWork 2000. The Key Action II Annual Conference. Madrid

2. BBJ Consult AG (Eds.).(2002): Wissensmanagement-Planspiel fur soziale Organisationen: Abschlussdokumentation. Mänchen

3. Bosch-Sijtsema, P. (2001): Knowledge development in a Virtual organisation: an Information Processing Perspective, Licentiate dissertation from Lund University, KFS AB Lund, Sweden

4. Büchel, B.;Probst, G.(2002): From Organizational Learning to Knowledge Management. Genf. 2000. WWW- 
Seite:http://hec.info.unige.ch/recherches_publications/OL\%20Article\%20for\%20Encyclopedia\% 20for\%20Life\%20Support\%20Systems1.pdf. 16.11 .

5. Camarinha-Matos, M.; Afsarmanesh, H., 1999. The virtual enterprise concept In: L.M. CamarinhaMatos and H. Afsarmanesh, Editors, Infrastructures for Virtual Enterprises-Networking Industrial Enterprises, Kluwer Academic Publishers, pp. 3-14

6. Goffin, K.; Mitchell, R.(2002): "Teaching Innovation and New Product Development using the "City Car" Simulation" 13th Annual Meeting of the Production and Operations Management Society, San Francisco 5th-8th April

7. KITS: Webpages of the KITS Project describing the simulation game KM-Quest. WWW-page. www.kmquest.nl/index.html. 03.01 .03

8. Larsson, R.; Bengtsson, L.; Henriksson, K.; Sparks, J. (1998): The Interorganizational Learning Dilemma: Collective Knowledge Development in Strategic Alliances. In: Special issue: Managing Partnerships and Strategic Alliances, in Organization Science Vol. 9, pp: 285-306

9. Nonaka, I. (1994):A dynamic Theory of Organizational Knowledge Creation, in: Organization Science, Vol 5

10. Pawar, K.S., Thoben, K-D. and Oehlmann, R. (1995). Developing concurrent engineering conceptual model and knowledge platform. In: Proceedings of the second conference on Concurrent Engineering, Research and Application (CERA). USA: Washington DC. 23-25 August. pp. 487497

11. Riedel, J.; Pawar, K. S.; Barson, R.(2001): Academic and Industrial User Needs for a Concurrent Engineering Simulation Game. In: Concurrent Engineering: Research and Applications. 11.

12. Sumner, T., Domingue, J., Zdrahal, Z., Millican, A., Murray, J.(1999): Moving from On-the-Job Training towards Organisational Learning. Proceedings of the 12th Banff Knowledge Acquisition Workshop, Banff, Alberta, Canada, October, 16-22

13. Thoben, K.-D., Jagdev, H. and Eschenbaecher, J. (1999): Extended Products: Evolving Traditional Product concepts. Proceedings of the 7th International Conference on Concurrent Enterprising: Engineering the Knowledge Economy through Co-operation. Bremen Germany 27-29th June 2001, pp. 429-439.

14. Windhoff, G. (2001): Planspiele für die verteilte Produktion. Entwicklung und Einsatz von Trainingsmodulen für das aktive Erleben charakteristischer Arbeitssituationen in arbeitsteiligen, verteilten Produktionssystemen auf Basis der Planspielmethodik. Dissertation Bremen 